\title{
Medical Coverage of Cricket Matches
}

\author{
Akshai Mansingh
}

\section{ABSTRACT}

Cricket is played around the world, at all ages and grades. Medical coverage of cricket matches varies equally, depending on the location, grade of cricket, expertise and resources available. Whereas recommendations exist for International matches and tournaments, this may not even extend to first class matches in many countries. Few sports provide guidelines on minimum requirements of coverage of events, and none exist in cricket. This paper proposes minimum standards aimed at being appropriate for all regions and levels of cricket.

Keywords: Cricket, Cricket and medical, Event coverage, Medical coverage.

How to cite this article: Mansingh A. Medical Coverage of Cricket Matches. J Postgrad Med Edu Res 2015;49(4):182-185.

\section{Source of support: Nil}

Conflict of interest: None

\section{BACKGROUND}

Minimum medical requirements in covering a cricket match have been the focus of attention with the recent tragic events involving grave injuries and even death of high profile cricketers. The role of medical management of athletes varies from sport to sport, often due to a lack of established protocols. Sports like Rugby have instituted and constantly reviewed protocols on concussion management. ${ }^{1}$ However in Football, there has been a lot of discussion on the role of medical personnel, from blatant disregard by players to medical advice in the recent World Cup in Brazil, to demotion of the Chelsea team doctor this year, drawing criticism of the coach by the FIFA medical chief. ${ }^{2}$ Even in cricket, the omission of an Australian player due to concussion drew unnecessary attention and criticism. ${ }^{3}$ Lack of standards of medical coverage and medical protocols have allowed episodes like these take place.

The International Cricket Council (ICC) provides guidelines for minimum requirements in international matches, and has detailed medical plans for all competitions

\footnotetext{
Head

Department of Sports Medicine, University of the West Indies Jamaica, West Indies

Corresponding Author: Akshai Mansingh, Head, Department of Sports Medicine, University of the West Indies, Mona Jamaica, West Indies, Phone: 8769776714, e-mail: akshai. mansingh@uwimona.edu.jm
}

that it runs. However, what pertains at first class or lower grades varies significantly. The West Indies, e.g. is a collection of 14 mainly independent countries, with wide variations in available specialists and resources. Many countries may not have a physiotherapist, let alone one at a cricket match. This is similar in many cities worldwide, where first class cricket is being played. Availability of specialist sports doctors or sports physiotherapists, and of equipment varies from country to country, and is often dependent on the grade of cricket being played.

Different sports have varying medical requirements ${ }^{4-6}$ from very high level resuscitative and diagnostic equipment, to the presence of medical responders with basic equipment. This paper looks at minimum medical requirements at international matches, and proposes minimum standards for other grades, in the scenario that all resources are not available. Examples of some short falls experienced have been used to illustrate the points.

\section{MEDICAL COVERAGE IN INTERNATIONAL CRICKET}

Based on the guidelines of the ICC, International matches and competitions require very detailed medical plans. The plan has to take into account coverage of players from the time of arrival to the time of departure, with as much attention paid to off field facilities as those at the stadia. Areas to be addressed are hospitals and medical rooms, medical personnel, ambulances and equipment, payment arrangements. It is as important to state what is not available as well is what is offered so that if teams wish to make special arrangements on their own, they have adequate notice. Coverage of players including facilities should be separate from those for spectators.

\section{STADIUM COVERAGE}

At the stadium, there must be ease of access to the medical room and transfer to the dedicated medical facility.

- A dedicated medical room for players, stocked with specified lifesaving equipment and medications (Appendix 1). This should be separate from facilities for spectators and easily accessible.

- Transfer protocol to dedicated medical facility off ground. Clear routes out of the dressing room or ground. This should not be shared with spectators (e.g. elevators). Space for a player on a stretcher with equipment (e.g. oxygen cylinder) should be adequate. 
Appendix 1: Match day medical coverage

Minimum medical standards are required for all sporting events. Equipment and personnel must be present to prevent sudden cardiac death, and deal with common injuries and medical conditions.

Prior to commencement of a match (or tournament), there should be provision for:

1. Onsite/on-call medical doctor

2. Onsite ambulance fully equipped with basic life support and EMTs

3. Access to a referral center with advanced cardiac life support

4. Clear 'Chain of Survival'

- Written emergency response

- Clear contact person

- Access to automated external defibrillator

- Communication process clear for call and for help

A goal of less than 3 to 5 minutes from collapse to shock delivery is recommended.

\begin{tabular}{llllll}
\hline \multicolumn{5}{c}{ Recommended personnel } \\
\hline \multirow{4}{*}{ Event } & Fully & On & On & On site & On call \\
& equipped & site & call & sports & sports \\
ambulance* & SpPT & SpPT & doctor & doctor
\end{tabular}

\begin{tabular}{|c|c|c|c|c|c|}
\hline $\begin{array}{l}\text { International } \\
\text { tests, one } \\
\text { day inter- } \\
\text { national, T20 }\end{array}$ & $x$ & $x$ & - & $x$ & - \\
\hline $\begin{array}{l}\text { First class } \\
4 \text { days, } \\
\text { one day } \\
\text { international }\end{array}$ & $x$ & $x$ & - & - & $x$ \\
\hline First class T20 & $x$ & $x$ & - & $x$ & 一 \\
\hline A team match & $x$ & $x$ & - & - & $x$ \\
\hline $\begin{array}{l}\text { Women } \\
\text { International }\end{array}$ & $x$ & $x$ & - & - & $x$ \\
\hline $\begin{array}{l}\text { Women } \\
\text { regional }\end{array}$ & $x$ & $x$ & - & - & $x$ \\
\hline Under 19 & $x$ & $x$ & - & - & $x$ \\
\hline Under 17 & $x$ & - & $x$ & - & $x$ \\
\hline Under 15 & $x$ & - & $x$ & - & $x$ \\
\hline
\end{tabular}

${ }^{*}$ Fully equipped ambulance must:

- Have trained EMTs

- Contain the equipment required for match coverage if this is not present at the PMOA medical center

**Sports physiotherapist

\begin{tabular}{ll}
\hline List of equipment available at all centers of training and play \\
\hline Minor wounds & Dressing pack \\
\hline Irrigation fluid (saline sterile) \\
Forceps \\
Scissors \\
Steri-strips \\
Suture kit \\
Tissue glue \\
Cleaning solution \\
Sterile gloves \\
Sterile gauze \\
Razor \\
Transparent dressing covers \\
1 or $2 \%$ lidocaine \\
Water for injection \\
Micropore/transpore \\
\end{tabular}

Contd...
Contd...

\begin{tabular}{ll}
\hline Minor wounds & Dressing pack \\
\hline Cardiac & AED \\
& Oxygen \\
& Bag and mask \\
& Airways
\end{tabular}

Intubation tray, laryngoscope,

ET tubes 6.5, 7, 7.5

Nasopharyngeal airway

Adrenaline 1 in 1000

Atropine

IV solutions $0.9 \%$ normal saline

Respiratory

Oxygen

Nebulizer

Ventolin (salbutamol)/saline availability

Cervical collar

Spinal board with appropriate straps for immobilization Irrigation fluid

Eye pads

Otoscope

Auroscope

Tongue depressor

Dental

Urinary

Musculoskeletal

Hanks solution

(milk as an option)

Dipstick

Refractometer

Tapes

Prewrap

Coban

Athletic tape

Splints

Crepe/elastic bandages

NSAIDs

Analgesics

Antiemetics/GI

Gravol

Antidiarrheal

Zantac

PPIs

Oral rehydration salts

Hypoglycemic

$50 \%$ dextrose solution

Capillary glucose meter

Allergic reaction management Hydrocortisone

Piriton

Adrenaline 1 in 1000

Flu management

Paracetamol

Cough suppressant

Antibiotics

5. Specific referral center for specialist care

- Cardiac

- Respiratory

- Neurological 


\begin{aligned} & \hline Contd... \\ & \hline - Orthopedic \\ & - Internal medicine \\ & - Dental surgeon \\ & - Ultrasound \\ & - MR scan scan \\ & - X-rays \\ & Require name of doctor, telephone contact numbers, location \\ & of office. \\ & \hline\end{aligned}

There have been instances where transfer of players has been delayed as the elevator is common with spectators and caterers. In another case, the area required for a player on a stretcher in an elevator was never considered, as the stretcher was always carried into the dressing room area vertically. Many minutes were spent figuring out alternative routes!

\section{Personnel}

Most international teams now have full time sports physiotherapists, and a growing number are travelling with team doctors. In such cases, there needs to be prearranged meetings with the local doctors and Physiotherapists to ensure that all requirements are fulfilled. If the team lacks either specialist, the ground should provide the following:

- Specialized sports medicine physician should be at the ground at all times and have access to players when needed. All security clearance regarding the players and match official areas should be sorted out prior to the match.

- Sports physiotherapist should be present at all times.

\section{Equipment}

Facilities differ from having near hospital like facilities to bare rooms. Bare minimum requirements include those listed in the Appendix 1. Other necessities include the following:

- Dedicated ambulance with trained emergency medical technicians (EMT)

- Examination beds and sheets

- Automated electric defibrillators (AED)

As simple as it may sound, there are venues where the ambulances may lack even the most basic resuscitation equipment. Many times, the personnel accompanying the ambulance are unable to handle a stretcher.

\section{Referral Facility/Personnel}

Volunteerism and courtesies are not to be assumed everywhere. Wait times and embarrassment can be minimized with proper organization and clearance ahead of time.
The following should be aware and amenable to treat players preferentially:

- Hospital: A tertiary level hospital in proximity to the stadium should be contacted and aware of the possibility that players may need treatment. All payment and other protocols should be sorted out in advance.

- Radiological facility: Inevitably there is need for some type of radiological investigation. If the facility is separate to the hospital, it too should have formalities streamlined in advance. The assumption is that $X$-rays, Ultrasound and magnetic resonance imaging (MRI) scanners would be available. It is important to alert teams in advance if any of these are not available.

- Medical specialists in all commonly accessed medical disciplines should be identified and alerted of the possibility of being called to see a player. If a specialty is not available, this should be brought to the attention of the team well in advance.

It is recommended that these facilities be as near to the stadium as possible, minimizing time away from the game. Cases, such as the test batsman, who was whisked away to a MRI facility hours away from the ground (by passing many on the way), resulting in the team batting one short as he could not come back in time for the close of innings must not be seen again. In that particular case, the secretary who typed the report was on leave for 2 days, resulting in the results being withheld for 2 days.

\section{OFF-FIELD COVERAGE}

\section{Practice Facility}

Coverage at practice facilities vary greatly. Where the following is not present, teams should be informed in advance so that they may make private arrangements if they wish to have them in place.

- Ambulance with resuscitative equipment (Appendix 1) and trained EMT

- On site physiotherapist (if teams do not have one)

- On call doctor.

\section{Hotel}

- On site medical room

- On site nurse

- On call doctor

Whereas the above-mentioned would be ideal at all cricket matches at all times, this is not always the case. The quest to spread the game to as many locations as possible is sometimes at the cost of availability of basic medical resources. The minimum requirements recommended for first class and lower grade matches may have to be altered. 


\section{FIRST CLASS CRICKET}

\section{Ground}

Dedicated private medical room.

\section{Personnel and Equipment}

- On site sports physiotherapist

- On call doctor

- On site ambulance with trained EMT

- Basic life saving equipment (AED, etc.) and first aid kit.

\section{Referral Facility/Personnel}

- Referral hospital

- Referral radiology facility

- On call specialists.

\section{GRADE CRICKET}

As the grade of cricket gets lower, the likelihood of having complete medical coverage diminishes. The following is suggested as the minimum requirement:

- First aid bag (list content) including AED

- BLS certified personnel (perhaps the coach)

- Identified transport to a medical facility

- Referral medical center.

Many countries have legislated minimum medical standards for coverage of any sporting event, and these should be adhered to. Unfortunately, many more places have no recommendations, and this serves as a guide. It tries to balance the realities of many cricket playing nations with the basic necessities of keeping the sport safe. As was seen in the tragedy involving Phillip Hughes, even with all possible resources and personnel, not every case may be saved but atleast morbidity and even mortality can be minimized.

\section{REFERENCES}

1. Fuller G, Kemp S, Decq P. The International Rugby Board (IRB) pitch side concussion assessment trial: a pilot test accuracy study. Br J Sports Med 2015;49:529-535.

2. Available at: http://www.supersport.com/Football/ barclays-premier-league/news/150821/Fifa_medical_chief_ backs_Chelsea_doctor

3. Available at: http://www.heraldsun.com.au/sport/australian-opener-chris-rogers-ruled-out-of-first-test-against-westindies-with-concussion/story-fni2u98u-1227378863908.

4. Medical support for hosting events and games. Olympic sport medicine manual; 2010. p. 453-468.

5. Dvorak J, Kramer E, et al. The FIFA medical emergency bag and FIFA 11 steps to prevent sudden cardiac death: setting a global standard and promoting consistent football field emergency care. Br J Sports Med 2013;47:1199-1202.

6. McDonagh D, editor. 2012. FIMS Sports medicine manual: event planning and emergency care ISBN: 978-58255-873-8. Wolters Kulwer Health/Lippincott Williams and Wilkins; 2011. 